\title{
AKTIVITAS ANTIBAKTERI DAUN KIRINYUH (Chromolaena odorata (L.) R.M.King \& H.Rob.) TERHADAP BAKTERI GANGREN
}

\author{
Media Yutika, Rolan Rusli, Adam M. Ramadhan \\ Laboratorium Penelitian dan Pengembangan FARMAKA TROPIS Fakultas Farmasi \\ Universitas Mulawarman, Samarinda, Kalimantan Timur \\ email: mediayutika@gmail.com
}

\begin{abstract}
Chromolaena leaves extract have antibacterial activity. The aim of this research is to determine antibacterial activity of Chromolaena leaves extract against gangrene bacteria was cultivated from pus of diabetic gangrene patient. Antibacterial activity was performed by agar diffusion method used a paper disk. Concentration of ethanol extract of Chromolaena leaves were 5\%, 10\%, 15\%, 20\%, 25\%, and 20\%. Aquadest was used as a negative control. The result showed that antibacterial activity of ethanol extract of Chromolaena leaves was categorized as moderate with value of inhibition was 5-10 mm. The best concentration of extract of Chromolaena leaves against the bacteria gangrene was $30 \%$.
\end{abstract}

Key words: Chromolaena leaves, gangrene bacteria, antibacterial.

\begin{abstract}
ABSTRAK
Daun kirinyuh mempunyai aktivitas antibakteri. Penelitian ini bertujuan untuk mengetahui aktivitas antibakteri ekstrak etanol daun kirinyuh terhadap bakteri luka gangren yang dikultivasi dari nanah luka penderita gangren diabetik. Metode yang digunakan untuk pengujian aktivitas antibakteri adalah metode difusi agar menggunakan paper disk. Konsentrasi ekstrak etanol daun kirinyuh yang digunakan yaitu 5\%, 10\%, 15\%, $20 \%, 25 \%, 30 \%$, dan aquades sebagai kontrol negatif. Hasil penelitian menunjukkan adanya aktivitas daya hambat dari ektrak daun kirinyuh tersebut Kategori kekuatan daya hambat dari ekstrak yaitu termasuk kategori sedang (5-10mm). Konsentrasi terbaik terdapat pada konsentrasi $30 \%$.
\end{abstract}

Kata kunci: Chromolaena odorata, bakteri penginfeksi luka gangren, antibakteri.

\section{PENDAHULUAN}

Diabetes millitus adalah penyakit metabolik yang ditandai dengan hiperglikemia akibat kerusakan proses sekresi atau insulin, atau keduanya. Organisasi Kesehatan Dunia (WHO) memprediksikan bahwa jumlah pasien diabetes di Indonesia akan meningkat dari 8,4 juta pada 2000 menjadi 21,3 miliar tahun 2030. International Diabetes Federation (IDF) juga memprediksikan kondisi serupa. Prevalensi diabetes mellitus di Indonesia adalah 5,7\% di 2010. Diabetes saat ini mempengaruhi lebih dari 194 juta orang di seluruh dunia dan diperkirakan akan mencapai 333 juta pada tahun 2025 yang banyak terjadi di negara-negara berkembang [1]

Diabetes mellitus dapat menyebabkan komplikasi Diabetic Foot Ulcer (DFU) atau gangren diabetik. Hal tersebut dikarenakan trauma akibat benda tajam yang tidak disadari 
oleh penderita. Luka tersebut akhirnya menjadi infeksi akibat adanya pertumbuhan mikroorganisme yaitu jenis aerob (gram positif dan gram negatif) dan jenis anaerob. Darah pada penderita diabetes mengandung glukosa yang tinggi. Kandungan glukosa tersebut merupakan media pertumbuhan yang cocok untuk mikroorganisme penginfeksi tersebut [2]

Infeksi merupakan masalah utama yang dialami oleh penderita gangren. Bakteri yang menyebabkan infeksi ini tergolong polimikrobial yang biasanya terdiri dari bakteri gram negatif aerob, gram positif aerob dan bakteri anaerob.

Pengobatan yang dilakukan untuk penderita DFU biasanya menggunakan antibiotik dari berbagai golongan yang dikombinasi. Namun, dari berbagai penelitian, antibiotik tersebut mengalami resistensi terhadap mikroorganisme penginfeksi.

Penggunaan bahan alam sebagai agen antibakteri mungkin bisa menjadi solusi untuk mengatasi infeksi tersebut. Daun kirinyuh secara empiris digunakan sebagai penyembuh luka. Kandungan metabolit sekunder daun kirinyuh antara lain adalah flavonoid, tannin, saponin, dan steroid [3] yang dapat memiliki aktivitas sebagai antibakteri. Penelitian ini dilakukan untuk mengetahui aktivitas antibakteri ekstrak daun kirinyuh $(C$. odorata) dalam menghambat pertumbuhan bakteri luka gangren yang di kultivasi dari nanah luka penderita gangren diabetik.

\section{METODE PENELITIAN}

\section{Bahan}

Bahan yang digunakan yaitu daun kirinyuh, etanol, kertas saring Whatman No. 42, Medium Na (Nutrien Agar) (Merck), medium Simmons Citrate Agar (Oxoid), medium Urea Agar (Oxoid), medium Lysine Iron Agar (Oxoid), medium Mannitol (Oxoid), medium Methyl Red (Oxoid), medium Kliger Iron Agar (Oxoid), $\mathrm{NaCl}$ 0,9\% (Widrata) dan air suling. Bakteri uji yang digunakan adalah bakteri penginfeksi gangren yang dikultivasi dari nanah gangren.

\section{Peralatan}

Peralatan yang digunakan yaitu wadah maserasi, rotary evaporator, water bath, timbangan analitik, cawan porselin, labu ukur, labu erlenmeyer, tabung reaksi, mikropipet, autoklaf, inkubator, cawan petri, spoit injeksi, micrometer skrup, LAF (Laminar Air Flow), dan alat penunjang lainnya.

\section{Prosedur}

Daun kirinyuh yang didapatkan di daerah Samarinda, dikeringkan kemudian diekstraksi dengan metode maserasi hingga diperoleh maserat. Maserat kemudian diuapkan pelarutnya hingga diperoleh ekstrak kental etanol.

\section{Kultivasi Bakteri Gangren}

Bakteri gangren diperoleh dari nanah pasien penderita diabetes gangren. Luka pasien dibersihkan terlebih dahulu menggunakan $\mathrm{NaCl}$. Kemudian swap transporter ditempelkan pada luka untuk mengambil nanah. Bakteri ditumbuhkan (kultivasi) pada medium NA dengan metode agar miring pada tabung reaksi dan diinkubasi pada inkubator selama $1 \times 24$ jam pada suhu $37^{\circ} \mathrm{C}$.

Hasil kultivasi bakteri kemudian dilakukan pengujian reaksi biokimia menggunakan medium Simmons Citrate Agar (SCA), Urea Agar, Lysine Iron Agar (LIA), Mannitol, Methyl Red, dan Kliger Iron Agar (KIA) untuk memastikan kandungan bakteri yang ada. 


\section{Persiapan Bakteri Uji}

Bakteri hasil kultivasi ditanam pada medium agar miring dan diinkubasi selana $1 \times 24$ jam dengan suhu $37^{\circ} \mathrm{C}$. Kemudian dibuat suspensi dengan menggunakan $\mathrm{NaCl} 0,9 \%$ sampai pengenceran 1:40.

\section{Pengujian Aktivitas Antibakteri}

Pengujian aktivitas antibakteri ekstrak daun kirinyuh dilakukan dengan metode difusi agar menggunakan paper disk. Suspensi bakteri sebanyak 0,02 $\mathrm{mL}$ dan medium NA sebanyak $10 \mathrm{~mL}$ dimasukkan ke dalam cawan petri dengan menggunakan metode spread palte. Paper disk tersebut direndam di dalam ekstrak etanol daun kirinyuh, lalu diletakkan di atas medium sebanyak 5 paper disk. Kontrol negatifnya menggunakan aquades. Kemudian diinkubasi selama $1 \times 24$ jam dengan suhu $37^{\circ} \mathrm{C}$.

\section{HASIL DAN PEMBAHASAN}

\section{Identifikasi kualitatif bakteri gangren}

Hasil identifikasi bakteri pada nanah luka gangrene pada beberapa medium menunjukkan hasil reaksi positif. Hasil reaksi positif ini ditunjukkan oleh adanya perubahan warna pada medium, seperti terlihat pada Gambar 1. Hasil reaksi positif dengan menggunakan beberapa medium tersebut menunjukkan bahwa pada nanah luka gangren diperoleh beberapa bakteri, yaitu Citrobacter, Enterobacter, Klebsiella, Escherichia, Shigella, Enterobacter aerogenes, E.coli, Klebsiella pneumonia, Proteus mirabilis, Proteus vulgaris, Staphlococcus epdermidis, Enterobacter aerogenes seperti dirangkum dalam Tabel 1.
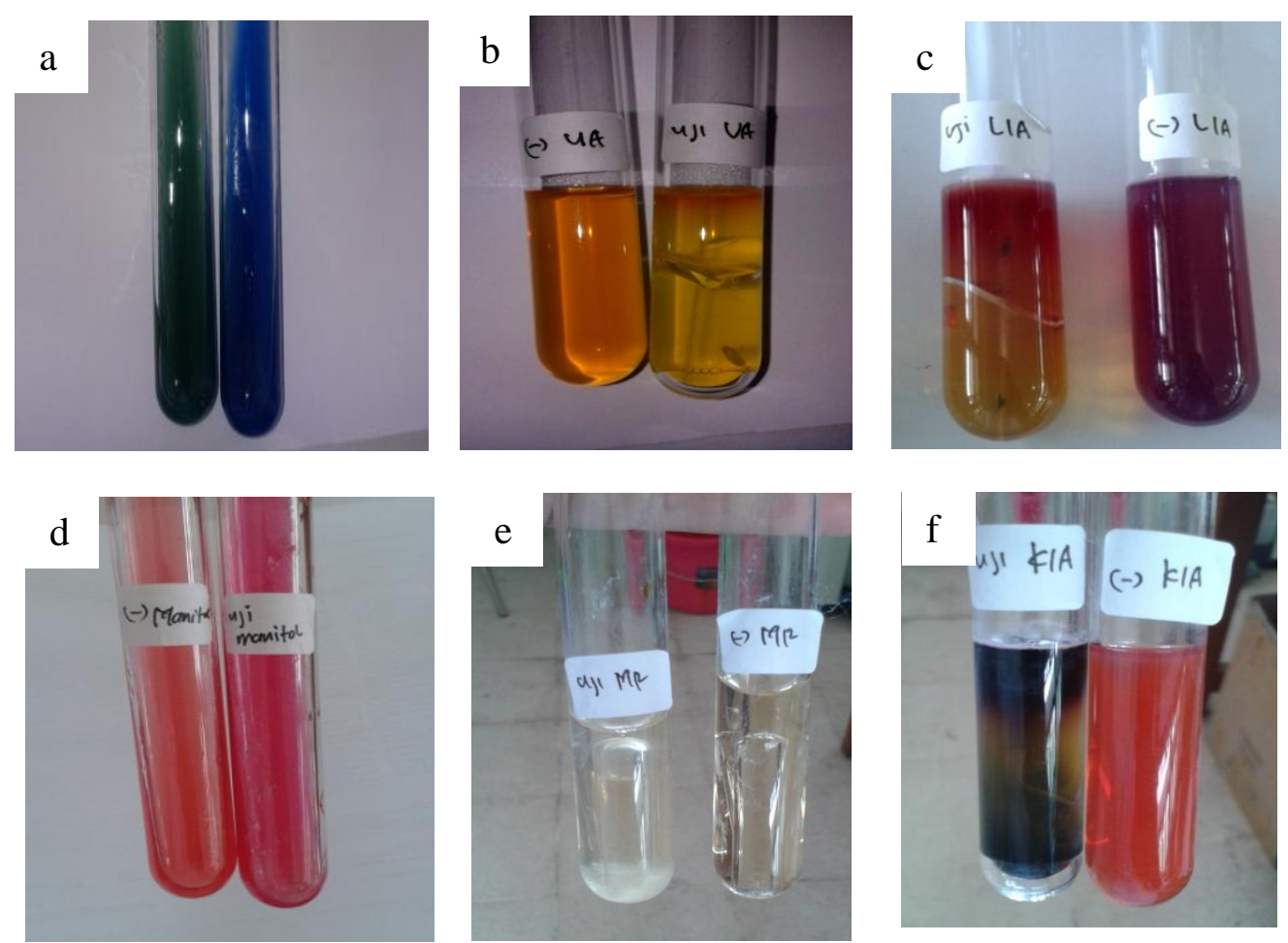

Gambar 1. Uji reaksi biokimia dengan medium (a) Simmons Citrate Agar, (b) Urea Agar, (c) Lysine Iron Agar, (d) Mannitol, (e) Methyl Red, dan (f) Kliger Iron Agar. 
Tabel 1. Uji Kualitatif Bakteri Pada Nanah Luka Gangren

\begin{tabular}{|c|c|c|}
\hline Medium uji & $\begin{array}{c}\text { Hasil } \\
\text { pengujian }\end{array}$ & Dugaan bakteri \\
\hline Simmsons citrate agar & + & $\begin{array}{l}\text { Citrobacter, Enterobacter, Klebsiella, } \\
\text { Escherichia, Shigella }\end{array}$ \\
\hline Urea agar & + & $\begin{array}{l}\text { Enterobacter aerogenes, E. coli, } \\
\text { Klebsiella pneumonia, Proteus Mirabilis, } \\
\text { Proteus vulgaris }\end{array}$ \\
\hline Lysine iron agar & + & Proteus vulgaris, Proteus mirabilis \\
\hline Mannitol & + & Staphlococcus epdermidis \\
\hline Methyl red & + & Enterobacter aerogenes \\
\hline Kliger iron agar & + & Citrobacter \\
\hline
\end{tabular}

Berdasarkan hasil identifikasi bakteri yang dilakukan pada nanah luka gangren dapat dikatakan bahwa hasil yang diperoleh berkesesuaian dengan yang dilaporkan oleh Swarn [2]. Swarn melaporkan bahwa bakteri penyebab gangren diabetik yaitu Staphylococcus aureus, Enterococcus spp, Coagulase negatif staphylococcus (CONS), Eschericia coli, Pseudomonas aeruginosa, Klebsiella pneumonia, Proteus spp, Acinetobacter spp, dan Citrobacter spp.

\section{Aktivitas antibakteri daun kirinyuh}

Pengujian aktivitas antibakteri ekstrak etanol daun kirinyuh terhadap bakteri luka gangren menggunakan konsentrasi 5\%, 10\%, 15\%, 20\%, 25\%, dan 30\%. Hasil pengujian dapat dilihat pada Gambar 2.
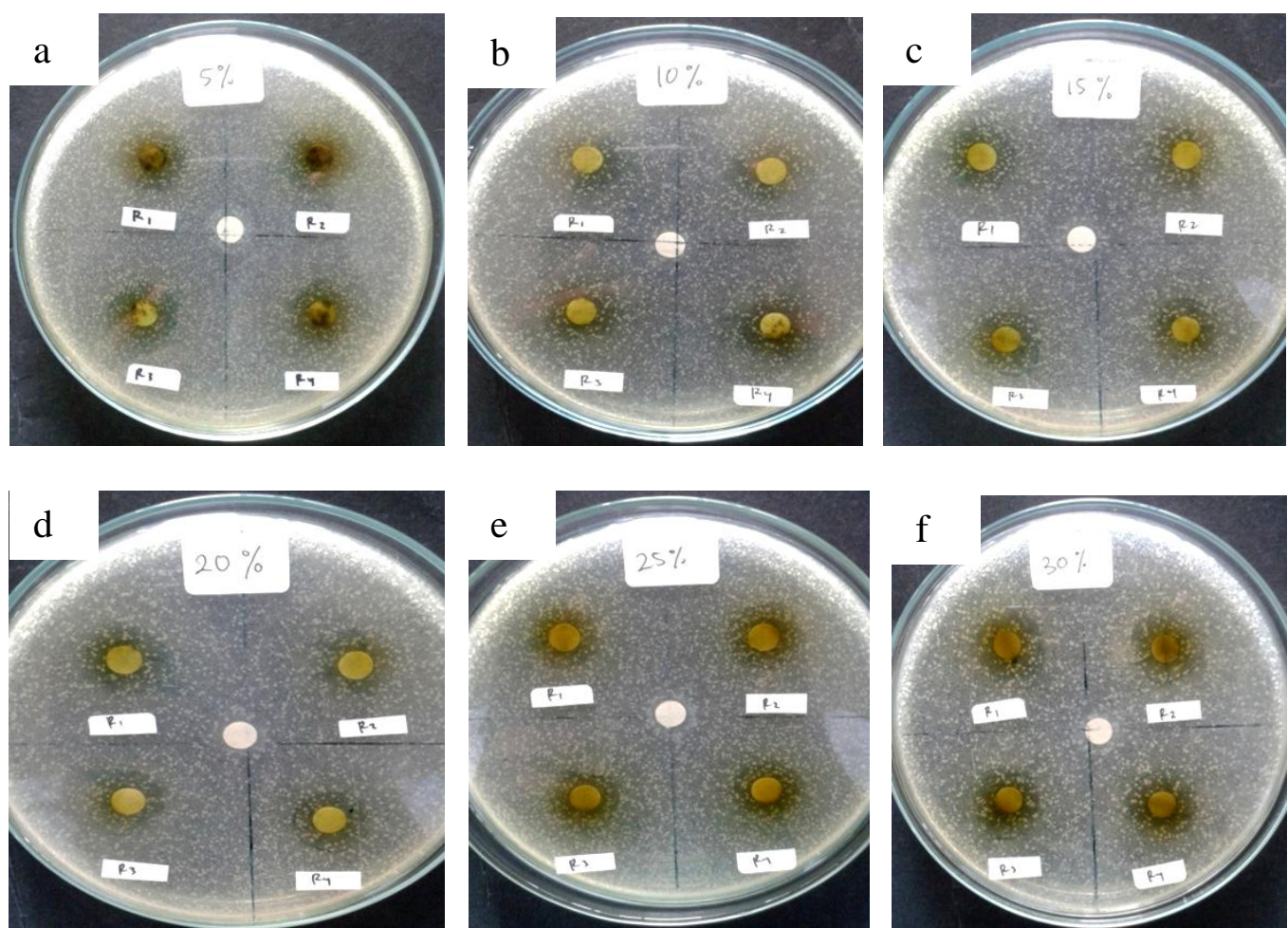

Gambar 2. Uji antibakteri ekstrak daun kirinyuh terhadap bakteri luka gangrene dengan konsentrasi ekstrak sebesar (a) $5 \%$ (b) $10 \%$ (c) $15 \%$ (d) $20 \%$ (e) $25 \%$, dan (f) $30 \%$. 
Gambar 2 menunjukkan adanya aktivitas antibakteri daun kirinyuh berupa terbentuknya zona hambat. Pada kontrol negatif (air suling) menunjukkan tidak terbentuknya zona hambat maupun zona bunuh, maka dapat disimpulkan bahwa zona hambat tersebut dihasilkan dari ekstrak daun kirinyuh dan bukan dari pelarut (air suling) yang digunakan.

Terlihat pada gambar terdapat 2 macam koloni, yaitu koloni berukuran besar dan kecil. Hal ini dikarenakan bakteri yang terdapat dalam cawan petri tersebut kompleks, seperti terlihat pada hasil identifikasi pada Tabel 1, dimana terdapat beberapa jenis bakteri baik itu bakteri gram positif dan gram negatif. Pada gambar 2 juga terlihat adanya aktivitas daya hambat yang bekerja hanya pada koloni bakteri yang berukuran kecil. Hal ini diduga karena kompleksitas bakteri yang ada pada koloni, sehingga ekstrak daun kirinyuh tidak dapat menghambat semua bakteri pada koloni yang ada, tetapi ekstrak daun kirinyuh hanya bekerja pada bakteri jenis tertentu. Namun hal ini perlu dieksplorasi lebih lanjut.

Selain itu, koloni bakteri yang berukuran besar tidak sensitif terhadap ekstrak daun kirinyuh diduga karena ukuran koloni bakteri yang besar sehingga bakteri yang terbunuh hanya bagian pinggir koloni saja sedangkan pada bagian tengah koloni tetap hidup, disebabkan oleh ekstrak yang tidak terserap hingga ke bagian tengah koloni karena ekstrak sudah digunakan untuk membunuh bagian pinggir koloni bakteri. Hal ini sejalan dengan yang diungkapkan oleh Poeloengan, dkk., (2005) dalam Purnama [4] bahwa faktor yang mempengaruhi penghambatan mikroorganisme terdiri dari kepadatan populasi mikroorganisme, kepekaan terhadap bahan antimikroba, volume bahan yang disterilkan, lamanya bahan antimikroba diaplikasikan pada mikroorganisme, konsentrasi bahan antimikroba, suhu dan kandungan bahan organik.

Aktivitas antibakteri berupa zona hambat yang dihasilkan oleh ekstrak etanol terhadap bakteri luka gangren dapat dilihat pada Tabel 2.

Tabel 2. Data aktivitas antibakteri ekstrak etanol daun kirinyuh

\begin{tabular}{cccc}
\hline \multirow{2}{*}{ Sampel uji } & Konsentrasi & \multicolumn{2}{c}{ Rerata Diameter $(\mathbf{m m})$} \\
\cline { 3 - 4 } Ekstrak etanol & $(\boldsymbol{\%})$ & Zona hambat & Zona bunuh \\
& 5 & 6,7351 & - \\
& 10 & 7,7212 & - \\
& 15 & 7,8230 & - \\
& 20 & 6,5892 & - \\
& 25 & 7,0690 & - \\
Air suling & 30 & 8,0837 & - \\
\hline
\end{tabular}

Menurut Daivis dan Stout (1971) dalam Purnama [4] mengatakan bahwa bila memiliki daerah hambat $20 \mathrm{~mm}$ atau lebih berarti memiliki kekuatan antibakteri sangat kuat; bila daerah hambatan yang dimiliki berkisar 10-20 $\mathrm{mm}$ berarti kuat; bila daerah hambatan 5-10 $\mathrm{mm}$ berarti sedang dan bila daerah hambatannya $5 \mathrm{~mm}$ maka aktivitas antibakteri tergolong lemah. Berdasarkan hasil pengamatan pada Tabel 2 dapat dikatakan bahwa ekstrak etanol daun kirinyuh termasuk dalam kategori sedang dalam penghambatan terhadap bakteri. 


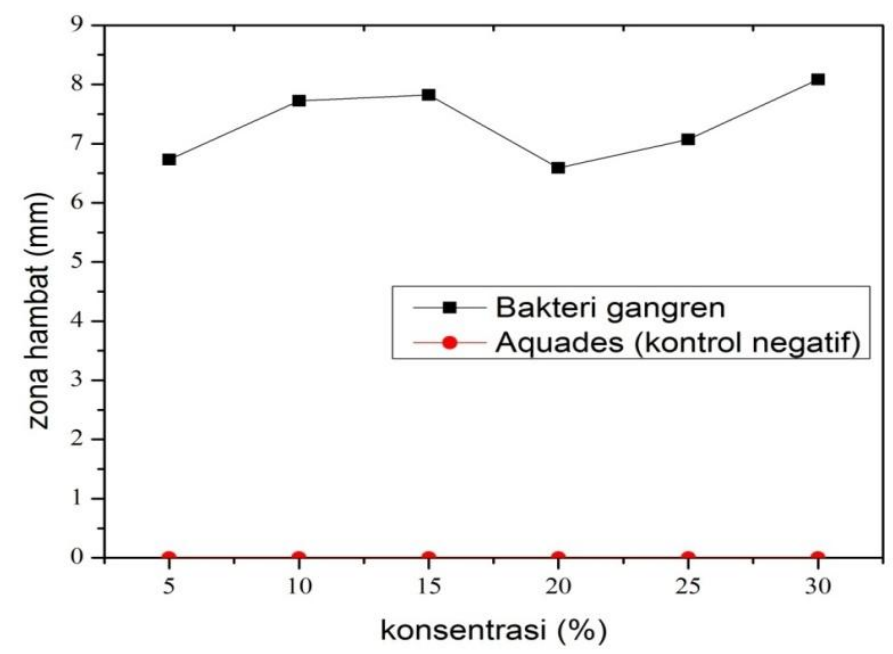

Gambar 3. Rata-rata diameter zona hambat ekstrak daun kirinyuh (C. odorata)

Pada gambar 3 terlihat aktivitas zona hambat setiap perlakuan tidak mengalami peningkatan yang sama. Hal ini sejalan seperti yang diungkapkan oleh Elifah (2010) dalam Istiqomah [5] bahwa zona hambat tidak selalu sebanding dengan naiknya konsentrasi. Hal ini terjadi karena perbedaan kecepatan difusi senyawa antibakteri pada media agar, jenis dan konsentrasi senyawa antibakteri yang berbeda juga memberikan zona hambat yang berbeda pada lama waktu tertentu. Faktor lainnya adalah akibat waktu pengeringan peper disk yang berbeda. Seperti yang diungkapkan oleh Panangan dan Nirman [6] bahwa kertas cakram yang pengeringannya cukup lama saat diletakkan di atas media pembenihan mikroba akan menghasilkan zona hambat yang kecil. Sedangkan jika dikeringkan dengan waktu yang sebentar saat diletakkan di atas media pembenihan mikroba, larutan yang menempel akan langsung menyebar di sekitar paper disk dan akan cepat berdifusi ke media agar membentuk zona hambat yang besar.

Konsentrasi terbaik merupakan konsentrasi ekstrak yang memberikan kemapuan terbaik dalam menghambat atau membunuh bakteri uji dibandingkna dengan konsentrasi lainnya. Konsentrasi terbaik tersebut dapat dilihat dari data zona bunuh atau zona hambat yang dianalisis dengan Anava satu arah dan dilanjutkan dengan uji Tukey HSD (Honestly Significant Diference). Hasil uji konsentrasi terbaik pada ekstrak daun kirinyuh terhadap bakteri luka gangren dapat dilihat pada Tabel 3.

Tabel 3. Konsentrasi terbaik ekstrak daun kirinyuh

\begin{tabular}{ccccc}
\hline \multirow{2}{*}{ Sampel uji } & Bakteri uji & \multirow{2}{*}{$\begin{array}{c}\text { Konsentrasi } \\
\text { terbaik }\end{array}$} & \multicolumn{2}{c}{ Diameter (mm) } \\
\cline { 4 - 5 } Ekstrak etanol & $\begin{array}{c}\text { Bakteri luka } \\
\text { gangren }\end{array}$ & $30 \%$ & 8,0837 & - \\
\hline
\end{tabular}

Berdasarkan Tabel 3 menunjukkan bahwa konsentrasi terbaik dari ekstrak etanol dalam menghambat bakteri luka gangren terdapat pada konsentrasi $30 \%$ yang menghasilkan zona hambat terbesar yaitu $8,0837 \mathrm{~mm}$ dibandingkan dengan konsentrasi 
lainnya. Sedangkan konsentrasi efektifnya terdapat pada konsentrasi 15\%. Menurut Bibiana [7] mengatakan konsentrasi efektif adalah zat antimikroba yang bersifat menghambat apabila digunakan dalam konsentrasi rendah dan bersifat membunuh apabila dalam konsentrasi yang tinggi.

\section{KESIMPULAN}

Hasil uji kualitatif bakteri pada nanah luka gangren yaitu positif pada semua medium uji, bakteri yang teridentifikasi adalah Enterobacter aerogenes, E.coli, Klebsiella pneumonia, Proteus mirabilis, Proteus vulgaris, Staphlococcus epdermidis, Enterobacter aerogenes. Ekstrak etanol daun kirinyuh mempunyai aktivitas antibakteri berupa zona hambat terhadap bakteri luka gangren. Konsentrasi terbaik ekstrak etanol daun kirinyuh adalah $30 \%$ dan konsentrasi efektifnya adalah $15 \%$.

\section{DAFTAR PUSTAKA}

1. Budiasih, K.S., Anwar, C., Santosa, S.J., Ismail, H., dan Sari, I.P., 2013. Antihyperglicemic Activity of Some Chromium(III)-Amino Acid Complexes in Nicotinamide-Streptozotocin Induced Diabetic Wistar Rats. Journal of Chemical and Pharmaceutical Research. 5. (9). 34-39

2. Swarna, S.R., Madhavan, R., Gomathi, S., dan Thamaraiselvi, S., 2012. A Study Of Biofilm On Diabetic Foot Ulcer. International Journal of Research in Pharmaceutical and Biomedical Sciences. 3. (4). 1809-1814.

3. Vital, Pierrangeli G Dan Windell L. Rivera. 2009. Antimicrobial Activity And Cytotoxity of Chromolaena Odorata (L.F) King and Robinson and Uncaria Perrottetii (A. Rich) Merr. Extracts. Journal of Medicinal Plants Research. 3. (7). 511-518

4. Purnama, Rahmad., Melki., Wike Ayu EP., dan Rozirwan. 2011. Potensi Ekstrak Rumput Laut Halimeda renchii dan Euchema cottonii Sebagai Antibakteri Vibrio Sp. Maspari Journal. 2. (1). 82-88

5. Istiqomah, Lusty., Ema Damayanti., Hardi Julendra., Dewi Istika., dan Sri Winarsih. 2014. Daya Hambat Granul Ekstrak Cacing Tanah (Lumbricus rubellus) Terhadap Bakteri Patogenik Secara In Vitro. Jurnal Sains Veteriner. 32. (1). 93-103

6. Panangan, A dan N. Syarif. 2009. Uji Daya Hambat Asap Cair Pirolisis Kayu Pelawan (Tristatia abavata) Terhadap Bakteri E. coli. Jurnal Penelitian Sains. 9. (6). 30-32

7. Bibiana. 1994. Analisis Mikroba di Laboratorium. Raja Gravindo Persada. Jakarta. 